\title{
Asymmetric Discouragement in Asymmetric Contests
}

\author{
Christoph March \\ Marco Sahm
}

CESIFO WORKING PAPER NO. 6108

CATEGORY 13: BEHAVIOURAL ECONOMICS

SEPTEMBER 2016

An electronic version of the paper may be downloaded

- from the SSRN website:

- from the RePEc website:

- from the CESifo website: WwW.SSRN.com

www.RePEc.org

www.CESifo-group.org/wp 


\title{
Asymmetric Discouragement in Asymmetric Contests
}

\begin{abstract}
We provide new experimental evidence which suggests an asymmetric discouragement effect in lottery contests with heterogeneous abilities. Compared to a symmetric contest, subjects invest less effort when facing a stronger opponent, but they invest the same when facing a weaker opponent. Our results can be explained by a simple model of disappointment aversion.
\end{abstract}

JEL-Codes: C720, C920, D720.

Keywords: asymmetric contest, discouragement effect, disappointment aversion, laboratory experiment.

Christoph March

TU Munich

Arcisstraße 21

Germany - 80333 Munich

christoph.march@tum.de

\author{
Marco Sahm* \\ University of Bamberg \\ Department of Economics \\ Feldkirchenstraße 21 \\ Germany-96052 Bamberg \\ Marco.Sahm@uni-bamberg.de
}

*corresponding author

This version: September 22, 2016 


\section{Introduction}

Many economically relevant situations take the form of a contest in which participants compete for a prize by spending non-refundable effort which increases the likelihood of winning but does not guarantee victory (see e.g. Konrad, 2009). Contestants are rarely symmetric: they differ with respect to abilities, resources, or preferences, amongst others. Theory predicts that contestants invest less effort in an asymmetric than in a symmetric contest (Baik, 1994, Stein, 2002). Yet, empirical evidence on this so-called discouragement effect is mixed (Dechenaux et al., 2015).

In this paper, we provide new experimental evidence which suggests that the discouragement effect is asymmetric. Compared to the symmetric contest, participants invest less when facing a stronger opponent, but they invest the same when facing a weaker opponent. Furthermore, this asymmetry is the stronger the larger the prize of the contest. We are able to explain our findings by disappointment aversion (Bell, 1985, Köszegi and Rabin, 2006).

\section{Theory}

We consider a winner-take-all contest with two risk-neutral participants $i \in\{1,2\}$ who compete for a rent of size $R>0$. Each participant $i \in\{1,2\}$ has an initial wealth endowment $e_{i} \in \mathbb{R}_{+}$and can invest effort $x_{i} \in\left[0, e_{i}\right]$ in order to improve her probability of winning $p_{i}$. Given effort levels $x_{i}$ and $x_{j}$ for $j \neq i$, this probability is given by the contest success function $(\mathrm{CSF}) p_{i}:\left[0, e_{i}\right] \times\left[0, e_{j}\right] \rightarrow[0,1]$ with $p_{i}(0,0)=1 / 2$ and

$$
p_{i}\left(x_{i}, x_{j}\right):=\frac{\theta_{i} x_{i}}{\theta_{i} x_{i}+\theta_{j} x_{j}}
$$

for $x_{i}+x_{j}>0$, where $\theta_{i}>0$ expresses participant $i$ 's ability. ${ }^{1}$ Without loss of generality, we assume that $\theta_{1} \geq \theta_{2}$ and call participant 1 (2) strong (weak).

The contest is organized as a simultaneous move game with complete information, i.e. each participant knows her own as well as her opponent's ability. Taking the opponent's effort $x_{j}$ as given, participant $i \neq j$ chooses $x_{i}$ to maximize her expected payoff

$$
E \pi_{i}\left(x_{i}, x_{j}\right)=p_{i}\left(x_{i}, x_{j}\right)\left(e_{i}-x_{i}+R\right)+\left[1-p_{i}\left(x_{i}, x_{j}\right)\right]\left(e_{i}-x_{i}\right) .
$$

\footnotetext{
${ }^{1}$ This asymmetric CSF was given an axiomatic foundation by Clark and Riis (1998), following an earlier axiomatization of the symmetric form with $\theta_{1}=\theta_{2}$ by Skaperdas (1996).
} 
In the unique Nash equilibrium (Baik, 1994)

$$
x_{1}^{*}=x_{2}^{*}=\frac{\theta_{1} \theta_{2}}{\left(\theta_{1}+\theta_{2}\right)^{2}} R=\frac{\eta}{(\eta+1)^{2}} R,
$$

where $\eta \equiv \theta_{1} / \theta_{2} \geq 1$ denotes the relative difference in ability. In equilibrium, both participants submit the same effort even if asymmetric. Moreover, equilibrium efforts are decreasing in $\eta$ and reach a global maximum of $R / 4$ at $\eta=1$. Hence, larger asymmetry discourages both participants' efforts. Intuitively, as $\eta$ increases, the strong participant has an incentive to lower her effort since she can obtain the same probability of winning with less effort. On the other hand, the weak participant lowers her effort, since her marginal probability of winning decreases, i.e. her effort is less effective in improving her probability of winning.

\section{Experimental Design and Procedures}

We test the discouragement effect in an experiment with two treatments and four sessions each. A session proceeds as follows: In the first part, we elicit subjects' risk preferences using a multiple price list format similar to Holt and Laury (2002). ${ }^{2}$ Subjects then play 30 repetitions (rounds henceforth) of the basic contest game. In each round, subjects are randomly matched into pairs and each subject receives an endowment of $e_{i}=600$ points which she may invest to obtain lottery tickets. Subjects compete for a prize of $R=200$ points in the first 20 rounds (part 2) and for a prize of $R=1,000$ points in the last 10 rounds (part 3).

The two treatments differ in the number of lottery tickets subjects obtain for each point invested. In each round of treatment Symmetric, each subject receives one lottery ticket for each point invested. Accordingly, differences in ability are absent. In treatment Asymmetric, one subject in each pair receives one ticket per point $\left(\theta_{i}=1\right)$, whereas the other subject receives two tickets per point $\left(\theta_{j}=2\right)$. The assignment of abilities varies across rounds. A subject is assigned the same ability level in the first half of rounds for a given prize and switches to the other level for the second half. ${ }^{3}$

In each round, we remind each subject of her own and her opponent's assigned

\footnotetext{
${ }^{2}$ Each subject is presented with a table of ten ordered decisions between a safe amount of 180 points and a risky lottery which offers either 400 points or 0 points. The likelihood of receiving 400 points increases across the table from 0.1 in the first row to 1.0 in the last row. Subjects are required to select one of the options in each row (we do not allow for indifference). Probabilities are explained in terms of throws of a ten-sided dice.

${ }^{3}$ More precisely, we employ a median split of all participants in a given session according to the number of times subjects choose the safe amount in part 1. Subjects in the more (less) risk averse group are assigned the low (high) ability in rounds 1 to 10 and 21 to 25 and the high (low) ability in rounds 11 to 20 and 26 to 30 .
} 
ability level, and we inform her about the number of times she and her opponent selected the safe amount in part one. In addition, we provide several tools to assist subjects in their decision-making. First, the instructions contain six fictitious examples. Second, the computer interface offers subjects the opportunity to enter fictitious efforts for themselves and the other investor to learn about the resulting likelihoods of winning and losing the contest and the corresponding number of points at the end of the round.

The sessions took place at the experimental laboratory of the Technical University of Munich ("experimenTUM") in March and November 2015. Students from TU Munich were invited using the ORSEE recruitment system (Greiner, 2015). 22 to 26 subjects participated in each session. The experiment was programmed and conducted with zTree (Fischbacher, 2007).

Upon arrival at the lab, subjects were randomly assigned to cubicles that did not allow for any visual communication between them. Subjects were immediately asked to read the computer screen, which informed them about rules of conduct in the laboratory, the existence of the three parts, and that instructions for a given part would be distributed directly before its start. Once all subjects were seated, paper instructions for part 1 were distributed and subjects were given time to read them at their own pace. Instructions were then read aloud and subjects were permitted to ask questions. Once all subjects had submitted their ten decisions, paper instructions for the second part were distributed. Subjects were again given time to read them at their own pace before the instructions were read aloud. Instructions for part 2 were followed by a short quiz to check subjects' understanding. The experimenters controlled subjects' answers and explained mistakes in private if necessary. Afterwards, the 20 rounds of part 2 were run. Finally, subjects received short paper instructions for the third part and the third part was conducted in a similar way as the second one. ${ }^{4}$

At the end of the session, we randomly selected one out of the 10 decisions from part 1 , one each out of the first and the last ten rounds from part 2, and one round from part 3 for payment using a ten-sided dice. Points were converted into cash at the rate 1 point $=€ 0.01$ and added to a show-up fee of $€ 4.00$. Before collecting their earnings, we asked subjects to fill out a short questionnaire consisting of some demographic questions and some questions related to the experiment. Afterwards, subjects retrieved their earnings in private and left.

Session lasted 100 minutes on average. The average payment was $€ 28.42$ in treatment Symmetric, and $€ 27.83$ in treatment Asymmetric. Overall, we collected 5,760 effort choices submitted by 192 subjects.

\footnotetext{
${ }^{4}$ The instructions are available from the authors upon request.
} 


\section{Experimental Results}

Figure 1 displays the evolution of average effort levels across rounds. Panel a (b) contains the results for part 2 (3) where subjects compete for a prize of $R=200$ $(R=1,000)$ points. We find a clear downward trend in efforts when subjects compete for the low prize. Averaging across the first (last) five rounds, the average effort equals 71.7 (58.2) in treatment Symmetric, 72.9 (49.3) for weak subjects, and 83.5 (54.7) for strong subjects in treatment Asymmetric. ${ }^{5}$ By contrast, when subjects compete for the high prize, efforts in treatment Symmetric and efforts of strong subjects in treatment Asymmetric hardly change: the average effort equals 243.3 (256.2) in the first (last) three rounds of treatment Symmetric and 266.6 (261.1) for strong subjects in the first (last) three rounds of treatment Asymmetric. The average effort of weak subjects in treatment Asymmetric, however, increases from 155.0 in the first three to 230.3 in the last three rounds. ${ }^{6}$

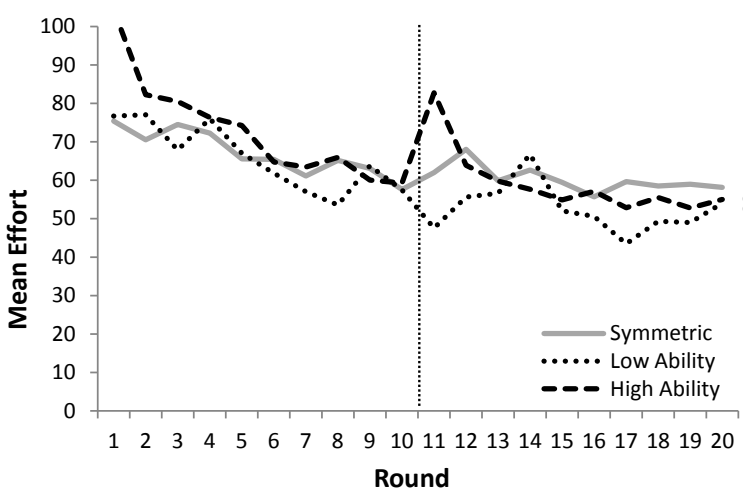

(a) Low prize

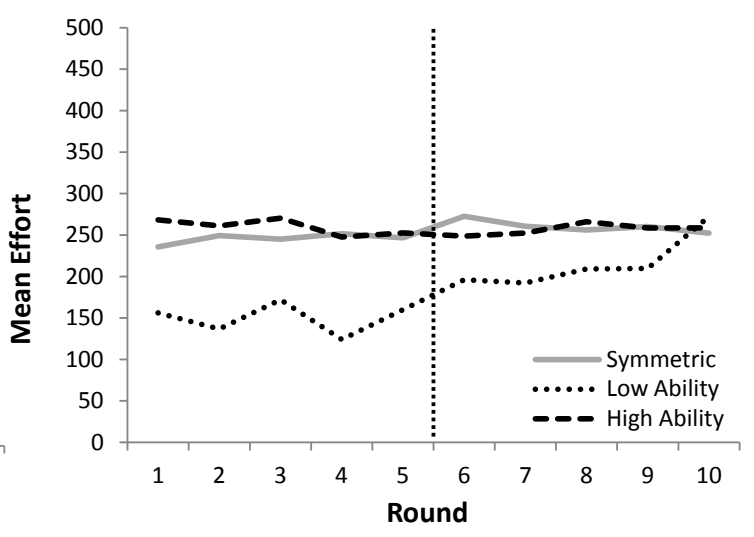

(b) High prize

Figure 1 Average efforts across rounds

Given these learning dynamics and our aim to test an equilibrium phenomenon, our data analysis will focus on late rounds, i.e. rounds 11 to 20 (6 to 10) in part 2 (3) of treatment Symmetric and rounds 6 to 10 and 16 to 20 (3 to 5 and 8 to 10) in part 2 (3) of treatment Asymmetric. Table 1 summarizes average effort levels across late rounds by treatment and size of the prize. While average efforts are lower in treatment Asymmetric than in treatment Symmetric, the difference is much larger for subjects of low ability. An increase in the opponent's ability yields a reduction

\footnotetext{
${ }^{5}$ The spikes in round 11 of treatment Asymmetric coincide with the change in abilities.

${ }^{6}$ The reported changes of efforts for subjects competing for the low prize and weak subjects competing for the high prize are significant based on the estimation of a random effects model of efforts which includes as explanatory variables the inverse of the round, dummies for the low and the high ability in treatment Asymmetric, and interactions. The findings are also corroborated by evidence on decision times and the use of the decision support tool. Detailed results are available from the authors.
} 
in efforts of $10.4 \%(26.5 \%)$ if the prize is low (high). In contrast, the reduction is negligible for an increase in own ability ( $1.7 \%$ and $0.5 \%$, respectively).

Table 1 Average effort in late rounds

\begin{tabular}{llclc}
\hline \hline Treatment/participant Type & \multicolumn{2}{l}{ Low Prize $(R=200)$} & \multicolumn{2}{l}{ High Prize $(R=1,000)$} \\
\hline Symmetric & 60.3 & $(45.6)$ & 260.3 & $(149.4)$ \\
Asymmetric: $:$ Weak & 54.0 & $(66.1)$ & 191.2 & $(208.6)$ \\
Asymmetric: Strong & 58.7 & $(37.5)$ & 259.0 & $(141.3)$ \\
\hline \hline
\end{tabular}

Standard Deviations in Parentheses

To provide statistical evidence for the effects, we estimate panel regression models of the chosen effort level. The models include as explanatory variables dummies for the low and the high ability in treatment Asymmetric and they allow for subjectspecific random effects. In further specifications, we also incorporate the own and the opponent's number of safe choices in the first part of the experiment, and responses to our final questionnaire as control variables. ${ }^{7}$ The results are presented in Table 2.

Table 2 Panel regression results for effort in late rounds.

\begin{tabular}{lllllll}
\hline \hline & \multicolumn{3}{c}{ Low Prize } & \multicolumn{3}{c}{ High Prize } \\
Specification & $(1)$ & $(2)$ & $(3)$ & $(4)$ & $(5)$ & $(6)$ \\
\hline Constant & $60.297^{* * *}$ & $60.503^{* * *}$ & $30.926^{* *}$ & $260.344^{* * *}$ & $280.897^{* * *}$ & $90.138^{* * *}$ \\
& $(4.548)$ & $(5.719)$ & $(13.890)$ & $(6.012)$ & $(9.970)$ & $(29.737)$ \\
Low Ability & -6.286 & -6.245 & $-12.348^{* *}$ & $-69.166^{* * *}$ & $-65.104^{* * *}$ & $-74.127^{* * *}$ \\
& $(6.421)$ & $(6.199)$ & $(6.166)$ & $(12.127)$ & $(12.565)$ & $(18.834)$ \\
High Ability & -1.612 & -1.571 & -7.674 & -1.398 & 2.664 & -6.359 \\
& $(5.972)$ & $(5.829)$ & $(4.932)$ & $(21.542)$ & $(22.754)$ & $(25.654)$ \\
Own Risk Aversion & & -0.156 & 0.374 & & $-16.329^{* * *}$ & $-12.746^{* * *}$ \\
[Number of Safe Choices] & & $(1.457)$ & $(1.709)$ & & $(3.134)$ & $(4.075)$ \\
Opponent's Risk Av. & & -0.035 & -0.069 & & -2.701 & -2.420 \\
& & $(1.106)$ & $(1.175)$ & & $(3.022)$ & $(3.179)$ \\
Further Controls & No & No & Yes & No & No & Yes \\
Observations & 1,920 & 1,920 & 1,920 & 1,052 & 1,052 & 1,052 \\
\hline \hline
\end{tabular}

Note: Robust standard errors in parentheses, clustered at the session level. Significance level: ${ }^{* * *}(1 \%),{ }^{* *}(5 \%),{ }^{*}(10 \%)$.

The estimations confirm that, holding own ability constant, subjects exert lower effort if they face a stronger opponent than in the symmetric contest. This difference is significant for the high prize across all specifications, and for the low prize once we add controls. In contrast, efforts are never significantly different between the symmetric and the asymmetric contest as own ability increases while the opponent's ability remains constant. We conclude that the discouragement effect is only present for the less able participant, especially if the prize is high.

\footnotetext{
${ }^{7}$ Specifically, we control for age, gender, academic major, mother tongue, and self-assessments on generosity, ambition, frequency of participation in games of chance and board games, importance of winning the contest, and importance of the final payment in the experiment.
} 
Though an asymmetric discouragement effect has not been explicitly noticed in previous studies, our results are not an outlier. Anderson and Freeborn (2010), whose design may be interpreted as focusing on the more able player, find no significant difference between a symmetric contest and an asymmetric contest with $\eta=2$. Similarly, strong (low cost) subjects in Rockenbach and Waligora (2016, see Table 5) exert comparable effort in contests with $\eta \in\{1,2\}$, whereas weak (high cost) subjects exert substantially lower effort for $\eta=2$ than for $\eta=1$. Interestingly, both types of subjects exert lower effort if $\eta=4$ which suggests that the discouragement effect is fully present once asymmetry is sufficiently large. In contrast, Fonseca (2009) finds that subjects in a symmetric contest exert higher effort than both weak and strong subjects in an asymmetric contest with $\eta=7 / 3$. However, subjects compete for a very low prize of $£ 0.2(€ 0.35)$ in this study. ${ }^{8}$ Finally, Sunde (2009) and Franke (2012) find evidence for asymmetric discouragement using sports data.

\section{Disappointment Aversion}

Why are strong players reluctant to reduce their effort? Intuitively, being the favorite might induce a feeling of deserving to win. To capture this intuition, we rely on the idea of disappointment aversion (Bell, 1985, Köszegi and Rabin, 2006, Gill and Prowse, 2012). Accordingly, in addition to her payoff, a participant derives positive (negative) utility from receiving more (less) than expected.

Let $q_{i} \in[0,1]$ denote participant $i$ 's subjective probability of winning the contest, where we assume that $\theta_{i}>\theta_{j}$ implies $q_{i}>q_{j}$. Given her subjective expected payoff $\pi_{i}^{e}=e_{i}-x_{i}+q_{i} R$, participant $i$ 's utility is assumed to take the following form:

$$
u_{i}=\pi_{i}+\alpha \max \left\{\pi_{i}-\pi_{i}^{e}, 0\right\}-\beta \max \left\{\pi_{i}^{e}-\pi_{i}, 0\right\} .
$$

$\alpha$ measures a participant's elation, i.e. her marginal utility from receiving more than expected. In contrast, $\beta$ measures an participant's disappointment, i.e. her marginal disutility from receiving less than expected. To capture the common finding that "losses loom larger than gains", we assume $\beta>\alpha \geq 0$. Note that for $\alpha>0$ the model comprises a form of joy-of-winning (Sheremeta, 2010, Price and Sheremeta, 2011).

Solving for the (unique) Nash equilibrium by simultaneously maximizing the

\footnotetext{
${ }^{8}$ Asymmetric contests are also considered by Anderson and Stafford (2003) and Kimbrough et al. (2014). While the former study does not distinguish responses to asymmetry by subject type, the latter lacks a symmetric contest as a benchmark.
} 
participants' expected utilities

$$
E u_{i}\left(x_{i}, x_{j}\right)=e_{i}-x_{i}+p_{i}\left(x_{i}, x_{j}\right)\left[R+\alpha\left(1-q_{i}\right) R\right]-\left[1-p_{i}\left(x_{i}, x_{j}\right)\right] \beta q_{i} R
$$

yields the equilibrium efforts

$$
x_{i}^{D A}=\frac{\theta_{i} \theta_{j} \gamma_{i}^{2} \gamma_{j}}{\left(\theta_{i} \gamma_{i}+\theta_{j} \gamma_{j}\right)^{2}} R
$$

for $i, j \in\{1,2\}, i \neq j$, where $\gamma_{i}=1+\alpha+(\beta-\alpha) q_{i}>1$.

For $\theta_{1}>\theta_{2}$ and thus $\gamma_{1}>\gamma_{2}$, theory predicts four results in line with our empirical observations. First, $x_{1}^{D A}>x_{2}^{D A}$, i.e. the strong participant exerts higher effort than the weak participant. Second, $x_{1}^{D A}>x_{1}^{*}$, i.e. disappointment aversion increases the strong participant's effort (overbidding). Third, assume that $\gamma_{1}^{\text {sym }}=$ $\gamma_{2}^{\text {sym }}=\gamma$ in the symmetric contest which yields a common equilibrium effort of $x_{\text {sym }}^{D A}=\gamma R / 4 \geq R / 4$. Then, $x_{1}^{D A}>x_{\text {sym }}^{D A}$ if $\gamma_{1}$ is not too small and the difference in abilities is not too large. Hence, the discouragement effect is absent for a sufficiently disappointment averse strong participant. Fourth, $x_{2}^{D A}<x_{2}^{*}<R / 4<x_{s y m}^{D A}$ if $\gamma_{2}$ is not too large. Therefore, the discouragement effect is present and even stronger (underbidding) for the weak participant with (moderate) disappointment aversion.

\section{Concluding Remarks}

Our results are instructive from a policy perspective. An important issue in the contest literature are the social costs induced by rent-seeking activities. According to conventional wisdom, the discouragement effect implies that social costs might be reduced by highlighting differences between contestants. Our evidence indicates that such a policy may be less effective than suggested. Moreover, our results illustrate that releasing information on participants' heterogeneity may hurt a contest designer interested in a close contest.

\section{Acknowledgements}

We are grateful to Caroline Bach, Leonard Przybilla, Alexander Schlimm, and Christina Strobel for excellent research assistance. We also thank Thomas Daske, Christian Feilcke, Andreas Ostermaier, Lisa Planer-Friedrich, Rudi Stracke, and seminar audiences at University of Munich and Technical University of Munich. 


\section{References}

Anderson, Lisa R. and Beth A. Freeborn, "Varying the intensity of competition in a multiple prize rent seeking experiment," Public Choice, 2010, 143 (1-2), 237254.

- and Sarah L. Stafford, "An Experimental Analysis of Rent Seeking Under Varying Competitive Conditions," Public Choice, 2003, 115 (1-2), 199-216.

Baik, Kyung Hwan, "Effort Levels in Contests with Two Asymmetric Players," Southern Economic Journal, 1994, 61, 367-378.

Bell, David E., "Disappointment in Decision Making Under Uncertainty," Operations Research, 1985, 33, 1-27.

Clark, Derek J. and Christian Riis, "Contest success functions: an extension," Economic Theory, 1998, 11 (1), 201-204.

Dechenaux, Emmanuel, Dan Kovenock, and Roman M. Sheremeta, "A survey of experimental research on contests, all-pay auctions and tournaments," Experimental Economics, 2015, 18, 609-669.

Fischbacher, Urs, "z-Tree: Zurich Toolbox for Ready-made Economic Experiments," Experimental Economics, 2007, 10 (2), 171-8.

Fonseca, Miguel A., "An experimental investigation of asymmetric contests," International Journal of Industrial Organization, 2009, 27 (5), 582 - 591.

Franke, Jörg, "The incentive effects of levelling the playing field - an empirical analysis of amateur golf tournaments," Applied Economics, 2012, 44, 1193 - 1200.

Gill, David and Victoria Prowse, "A Structural Analysis of Disappointment Aversion in a Real Effort Competition," American Economic Review, 2012, 102, 469-503.

Greiner, Ben, "Subject pool recruitment procedures: Organizing experiments with ORSEE," Journal of the Economic Science Association, 2015, 1, 114-25.

Holt, Charles A. and Susan K. Laury, "Risk Aversion and Incentive Effects," American Economic Review, December 2002, 92 (5), 1644-1655.

Kimbrough, Erik O., Roman M. Sheremeta, and Timothy W. Shields, "When parity promotes peace: Resolving conflict between asymmetric agents," Journal of Economic Behavior \& Organization, 2014, 99, 96 - 108. 
Konrad, Kai A., Strategy and Dynamics in Contests, Oxford University Press, New York, 2009.

Köszegi, Botond and Matthew Rabin, "A Model of Reference-Dependent Preferences," Quarterly Journal of Economics, 2006, 121, 1133-1165.

Price, Curtis R. and Roman M. Sheremeta, "Endowment effects in contests," Economics Letters, 2011, 111, 217-219.

Rockenbach, Bettina and Marcin Waligora, "Desire to Win Drives Overbidding in Tullock Contests," mimeo, University of Cologne 2016.

Sheremeta, Roman M., "Experimental comparison of multi-stage and one-stage contests," Games and Economic Behavior, 2010, 68, 731-747.

Skaperdas, Stergios, "Contest success functions," Economic Theory, 1996, 7 (2), 283-290.

Stein, William E., "Asymmetric Rent-Seeking with More Than Two Contestants," Public Choice, 2002, 113, 325-336.

Sunde, Uwe, "Heterogeneity and performance in tournaments: a test for incentive effects using professional tennis data," Applied Economics, 2009, 41, 3199 - 3208. 